\title{
O USO DE UMA ATIVIDADE EXPERIMENTAL COMO RECURSO PEDAGÓGICO PARA AVALIAR AS DIFICULDADES DOS ALUNOS EM UM CONTEÚDO DE FÍSICA
}

\author{
Leonardo dos Santos Cunha ${ }^{1}$ \\ Maria Bethânia Fochi dos Santos ${ }^{2}$
}

\begin{abstract}
Resumo: Este trabalho traz uma proposta de avaliação pedagógica que utiliza os dados de uma atividade experimental para mapear as dificuldades dos alunos em um conteúdo específico para assim orientar a próxima prática pedagógica. Com um caráter verificativo, a atividade foi elaborada utilizando um experimento de movimento retilíneo uniforme, o qual, através de um roteiro orientado, gerou os dados necessários para ser feita uma análise técnica desses dados e retirar as informações importantes. Enfim, o resultado do trabalho mostra as latentes dificuldades dos alunos com o emprego de unidades e o entendimento de conceitos físicos básicos, o que aponta para a necessidade de se elaborarem atividades que venham sanar tais dificuldades.

Palavras-chave: Avaliação; Atividade experimental; Prática pedagógica.
\end{abstract}

\footnotetext{
1 Universidade Federal de Itajubá, Brasil. E-mail: leonardodosscunha@yahoo.com.br.

2 Universidade Federal de Itajubá, Brasil. E-mail: bethaniafochi@gmail.com.
} 